\title{
2018 Türkçe Dersi Öğretim Programı Kazanımlarının 21. Yüzyıl Becerileri Açısından İncelenmesi
}

\author{
Mehmet KURUDAYIOĞLU \\ Hacettepe Üniversitesi, Eğitim Fakültesi, Türkçe Eğitimi Bölümü, Ankara \\ mkurudayi@gmail.com \\ ORCID ID: https://orcid.org/0000-002-0447-5236 \\ Taşkın SOYSAL \\ Bolu Bilim ve Sanat Merkezi \\ taskinsoysal@gmail.com \\ ORCID ID: https://orcid.org/0000-0003-2753-5905
}

Araștırma Makalesi

Geliş Tarihi: 17.09.2019

Revize Tarihi: 22.11 .2019

DOI: $10.31592 /$ aeusbed.621132 Kabul Tarihi: 22.11.2019

\section{Atıf Bilgisi}

Kurudayığlu, M. ve Soysal, T. (2019). 2018 Türkçe dersi öğretim programı kazanımlarının 21. yüzyıl becerileri açısından incelenmesi. Ahi Evran Üniversitesi Sosyal Bilimler Enstitüsü Dergisi, 5(2), 483-496.

\section{ÖZ}

Bu çalışmanın amacı, 2018 yılında güncellenen Türkçe Dersi Öğretim Programı (1-8. Sınıf) kazanımlarının 21. yüzyıl becerilerinin yaşam ve kariyer becerileri (esneklik ve uyum yeteneği, girişimcilik ve özyönetim, sosyal ve kültürlerarası beceriler, verimlilik ve hesap verebilirlik, liderlik ve sorumluluk); öğrenme ve yenilikçilik becerileri (yaratıcılık, eleştirel düşünme, iletişim, iş birliği); bilgi, medya ve teknoloji becerilerine (bilgi okuryazarlığı, medya okuryazarlığı, bilgi ve iletişim teknolojileri okuryazarlığı) uygunluğu açısından incelenmesidir. Araştırma, nitel olarak desenlenmiştir. Çalı̧̧manın verileri doküman analizi yoluyla toplanmıştır. Araştırmada,Türkçe Öğretim Programı'ndaki (MEB, 2018) her bir kazanım P21'in çerçevesinde yer alan yaşam ve kariyer becerileri, öğrenme ve yenilikçilik becerileri ile bilgi, medya ve teknoloji becerileri ve bu başliklara bağlı alt becerilere uygunluğu bakımından incelemeye tabi tutulmuştur. Sonuç olarak öğrencilerimizin çağın ihtiyaçlarına cevap verebilen ve her geçen gün gelişen dünyaya ayak uydurabilecek donanımlı bireyler olmaları bakımından önem arz eden 21. yüzyıl becerilerine, güncellenen 2018 programına bağlı kazanımlarda yeterli ve dengeli düzeyde yer verilmediği tespit edilmiştir.

Anahtar Kelimeler: 21. yüzyıl becerileri, program, kazanım, yetkinlik.

\section{An Evaluation of 2018 Turkish Course Curriculum in terms of 21st Century Skills}

\begin{abstract}
The aim of this study is to examine in terms of suitability of the 21 st century skills, the life and career skills (flexibility and adaptability, entrepreneurship and self-management, social and intercultural skills, productivity and accountability, leadership and responsibility); learning and innovation skills (creativity, critical thinking, communication, collaboration); information, media and technology skills (information literacy, media literacy, information and communication technologies literacy) for Turkish Language Teaching Program (Grades 1-8) gains updated in 2018. The research is qualitatively designed. Data were collected through document analysis. In the research, each achievement in the curriculum (MEB, 2018) has been examined in terms of life and career skills, learning and innovation skills, knowledge, media and technology skills and sub-skills related to these titles within the framework of P21. As a result, it is seen that students who are able to respond to the needs of the age and who are capable of adapting to every day developing world, have not been given sufficient and balanced level in the 21st century skills which are important for 2018 program.
\end{abstract}

Keywords: 21 st century skills, program, gain.

\section{Giriş}

İçinde yaşadığımız çağda meydana gelen hızlı değişim, toplumda da birtakım değişiklikleri zorunlu hâle getirerek eğitimden sosyal yaşama birçok alanda yeni ihtiyaçların doğmasına sebep olmuştur. "21. yüzyılda, insanlık toplumsal, ekonomik ve kişisel seviyelerde ciddi zorluklarla karş1 karşıyadır." (Bialik ve Fadel: 2015, s. ii). Bu değişikliklerle başa çıkacak güç yine toplumun kendi içerisinden çıkacaktır ancak gerek birey gerek toplum gerekse millet olarak değişimin öncülüğünü yapmak, belirli bir kapasite gerektirmekle beraber bu kapasitenin ortaya çıkması da birtakım beceriler yoluyla olacaktır. McCoog (2008) 21. yüzyıl öğrencilerinin hem kendi kendini yöneten hem de bireyler, 
gruplar ve makinelerle iş birliği yapma yeteneğine sahip olmaları gerektiğini belirtmiş̧tir. Bu noktada karşımıza 21. yüzyıl becerileri çıkmaktadır.

Ercikan ve Oliveri (2016) 21. yüzyıl becerileri teriminin birçok yönden yorumlandığını ancak genel olarak modern toplumda ve iş gücünde önemli olan becerilerin bir kombinasyonunu ifade ettiğini belirtmişlerdir. 21. yüzyıl becerilerinin neler olduğuyla ilgili alan yazında hazırlanmış birçok çerçeve [Organization for Economic Co-Operation and Development (OECD), Assessment and Teaching of 21st Century Skills (ATCS) gibi] mevcuttur. Çerçevelerde ön plana çıkan dört becerinin iletişim, yaratıcılık, eleştirel düşünme ve problem çözme olduğu görülmektedir. Tanımlanan çok çeşitli diğer beceriler arasında da genel olarak bilgi teknolojileri ve sosyal beceriler yer almaktadır. Söz konusu çerçeveler arasında Partnership for 21st Century Skills'in (P21) hazırlamış olduğu çerçeve alanyazında daha fazla kabul görmektedir.

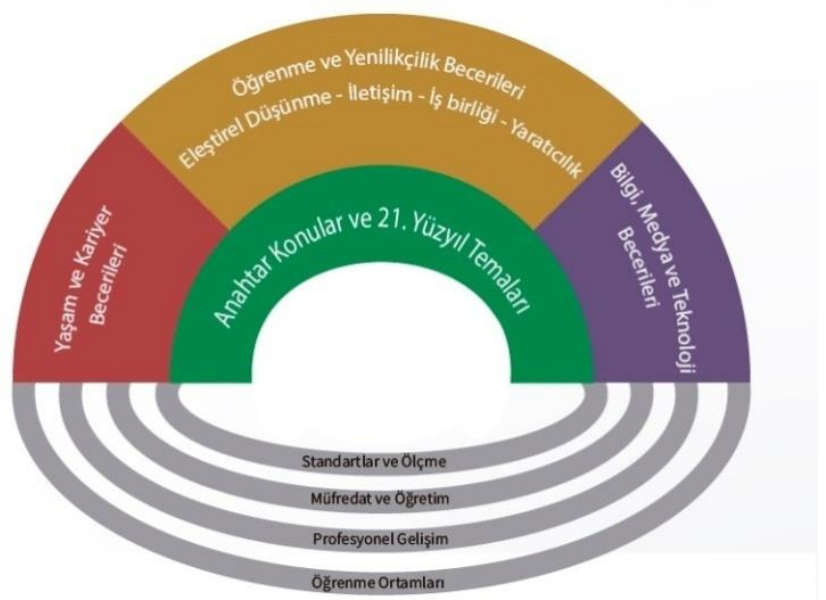

Şekil 1. P21 21. Yüzy1l Becerileri Çerçevesi

P21 Çerçevesi, 21. yüzyıl becerilerini eğitim ortamlarına dahil etmek amacıyla oluşturulmuş bir modeldir. ABD (Amerika Birleşik Devletleri) Eğitim Bakanlığından bir koalisyon ile Apple, AOL (America Online), Microsoft, Cisco gibi işletmeler ve NEA (National Education Association) gibi eğitime dahil olan kuruluşlar tarafından geliştirilmiştir. "21. Yüzyıl Öğrenimi için Ortaklık" olarak bilinen bu koalisyon, ilk kez 2006 yılında yayınlanmıştır ve güncellenmeye devam etmektedir.

P21'in hazırlamış olduğu çerçeveyi incelediğimizde becerilerin üç ana başlık altında toplandığını görüyoruz. Bunlar:

\section{Yaşam ve Kariyer Becerileri}

- $\quad$ Esneklik ve Uyum Yeteneği

- $\quad$ Girişimcilik ve Özyönetim

- $\quad$ Sosyal ve Kültürlerarasi Beceriler

- $\quad$ Verimlilik ve Hesap Verebilirlik

- $\quad$ Liderlik ve Sorumluluk

Öğrenme ve Yenilikçilik Becerileri

- $\quad$ Yaratıcilik

- $\quad$ Eleştirel Düşünme

- $\quad$ İletişim

- $\quad$ İş birliği

Bilgi, Medya ve Teknoloji Becerileri

- $\quad$ Bilgi Okuryazarlığ1

- $\quad$ Medya Okuryazarlığ1

- $\quad$ Bilgi ve İletişim Teknolojileri (ICT) Okuryazarlığ1 
$\mathrm{Bu}$ becerilerin kişinin toplumsal yaşamda daha etkin bir rol almasında ve günümüz dünyasının yoğun bilgi akışının yönetilmesinde önemi ortadadır. Çünkü 21. yüzyıl becerilerine sahip bireyler, çağın gerektirdiği ölçüde girişimci, kendi kendini yönetebilen, sorumluluk sahibi, lider vasıflı, üretken, olay ve durumlara farklı bakış açıları geliştirebilen sosyal bireyler olmalarının yanı sıra yaratıcı ve eleştirel düşünen, sağlıklı iletişim kurabilen ve takımlar içerisinde verimli bir şekilde çalışabilen aynı zamanda bilgi ve medya okuryazarı olmaları yönüyle de ön plana çıkan bir yapıya sahip olurlar. Bu yüzden günümüz bireyi, rekabetçi koşulların üstesinden gelerek içinde bulunduğu toplumun değerli bir üyesi olmak için 21. yüzyıl becerilerine yeterli düzeyde sahip olmalıdır.

21. yüzyıl becerileri ile ilgili en büyük eleştirilerden biri, bu becerilerin medya ve teknoloji becerileri haricinde geçmiş yüzyıllarda ihtiyaç duyulan becerilerden farklı olmadığ 1 yönündedir. 21 . yüzyılda başarı için gerekli becerilerin birçok bakımdan geçmiş yüzyıllardan farklı olmadığı bir gerçektir. Ancak günümüz dünyasında insanoğlunun tarih boyunca ihtiyaç duyduğu bazı temel beceriler daha da önem kazanmıştır çünkü küresel bazda meydana gelen gelişmeler devam ederken buna bağlı olarak bilgi her geçen gün katlanarak artmakta, dolayısıyla günümüzün rekabetçi koşullarında ön plana ç1kmak için belirli yeterliklere sahip olmak gerekmektedir.

Lamb, Maire ve Doecke'ye (2017) göre becerileri tanımlamak zor olsa da bunlar özellikle politika yapıcıların, araştırmacıların ve uygulayıcıların yakından ilgisini çekmektedir. Çerçeveden de anlaşılacağı üzere 21. yüzyıl temaları standartlar ve ölçme, müfredat ve öğretim, profesyonel gelişme ve öğrenme ortamları ile de iç içe bir yapıya sahiptir. Buradan hareketle 21. yüzyıl becerilerinin yalnızca eğitim-öğretim ortamlanıla sınırlı kalmadığı, bu çerçevenin hayat boyu öğrenme anlayışıyla ortaya konulduğu görülmektedir.

21. yüzyıl becerilerinin yaşam boyu öğrenme anlayışıyla tasarlanmış olması öğretim ortamlarında da bu becerilere yer verilmesi ve öğrencilerin mezun olurken belirli yeterlikleri almasını gerektirmektedir. "21. yüzyıldaki eğitim küreselleşmeyi vurgulamaktadır. Teknolojideki herhangi bir gelişme, öğrenciler ve öğretmenler arasındaki bilgi, beceri ve tutumların geliştirilmesi ve iyileştirilmesinde teorik yapılar ve gerçekçi görüşler sunar" (Abao, Bohalono ve Dayagbil, 2015, s. 173). 21. yüzyıl becerileriyle ilgili bir diğer konu da öğrencilere bu becerilerin nasıl kazandırılacağıdır. Öğretim ortamlarında becerilerin kazandırılması ders kitaplarına konulacak her bir metin ve bu metinlere bağlı etkinlikler yoluyla olacaktır. Ders kitaplarının hazırlanmasında da öğretim programlarında yer alan kazanımlardan yola çıkılmaktadır. Daha önce yapılan çalışmalarda (Kurudayığlu ve Soysal, 2018; Temizkan, 2014) Türkçe dersi öğretim programlarının iddia ettikleri yetkinlik ve becerilerin ders kitaplarında yeterli ve dengeli bir şekilde yansımadığı sonuçlarına ulaşılmıştır. Bu durumda çağın gereklerine uygun, öğrencilerimizi içinde bulunduğu yüzyılda nitelikli bir insan yaparken aynı zamanda gelecek yüzyıl için de kıymetli bir toplum oluşmasını sağlayacak programlara ihtiyaç duyulmaktadır. 2018 Türkçe Dersi Öğretim Programı'nda (İlkokul ve Ortaokul 1, 2, 3, 4, 5, 6, 7 ve 8. Sınıflar) Türkiye Yeterlilik Çerçevesi (TYÇ) kapsamında yer verilen yetkinlikler aşağıdaki gibidir:

- Ana Dilde İletişim

- Yabanci Dillerde İletişim

- Matematiksel Yetkinlik ve Bilim/Teknolojide Temel Yetkinlikler

- Dijital Yetkinlik

- Öğrenmeyi Öğrenme

- Sosyal ve Vatandaşlıkla İlgili Yetkinlikler

- İnisiyatif Alma ve Girişimcilik

- Kültürel Farkındalık ve İfade (MEB, 2018, ss. 4-5).

Görüldüğü üzere programın öğrencilere kazandırmak istediği yetkinlikler 21. yüzyıl becerileriyle kısmen örtüşmektedir. Bu anlamda yetkinliklerin ana ve yabancı dilde iletişim, dijital 
yetkinlik gibi 21. yüzy1l becerilerine temas eden bölümleri olduğu görülmektedir ancak yetkinlikler 21 . yüzyıl becerilerin bütününü kapsamamaktadır.

21. yüzyıl becerilerinin öğretim ortamlarındaki öneminden hareketle bu çalışmanın amacı 2018 yılında güncellenen Türkçe Dersi Öğretim Programı'na (İlkokul ve Ortaokul 1, 2, 3, 4, 5, 6, 7 ve 8. Sınıflar) ait her bir kazanımı P21'in çerçevesindeki becerilere uygunluğu bakımından incelemektir. Böylece Millî Eğitim Bakanlığının 2023 Vizyonu'nda da kendisine yer bulan 21. yüzyıl becerilerine programlarımızda ne kadar yer verildiği ortaya konulmuş olacaktır. Buna göre araştırmanın problem ve alt problemleri şu şekilde belirlenmiştir:

\section{Problem Cümlesi:}

2018 Türkçe Dersi Öğretim Programı (1-8. Sınıf) kazanımlarında 21. yüzyıl becerilerine yer verilmiş midir?

\section{Alt Problemler:}

1. 2018 Türkçe Dersi Öğretim Programı (1-8. Sınıf) kazanımlarında 21. yüzyıl yaşam ve kariyer becerilerine yer verilmiş midir?

2. 2018 Türkçe Dersi Öğretim Programı (1-8. Sınıf) kazanımlarında 21. yüzyıl öğrenme ve yenilikçilik becerilerine yer verilmiş midir?

3. 2018 Türkçe Dersi Öğretim Programı (1-8. Sınıf) kazanımlarında 21. yüzyıl bilgi, medya ve teknoloji becerilerine yer verilmiş midir?

\section{Yöntem}

Çalışma nitel olarak desenlenmiştir. "Nitel araştırma; gözlem, görüşme, doküman analizi gibi nitel veri toplama yöntemlerinin kullanıldığı, algıların ve olayların doğal ortamda gerçekçi ve bütüncül bir biçimde ortaya konmasına yönelik nitel bir sürecin izlendiği araştırma olarak tanımlanabilir" (Yıldırım ve Şimşek, 2016, s. 41). Buna göre 2018 Türkçe Dersi Öğretim Programı (1, 2, 3, 4, 5, 6 , 7 ve 8. Sınıflar) kazanımları tüm sınıflar düzeyinde 21. yüzyıl becerilerinin yaşam ve kariyer becerileri; öğrenme ve yenilikçilik becerileri; bilgi, medya ve teknoloji becerilerine göre nitel araştırma yöntemlerinden "doküman incelemesi”ne tabi tutulmuştur. Yıldırım ve Şimşek'e (2016) göre doküman incelemesi, hedeflenen olgu veya olgular hakkında bilgi içeren yazılı materyallerin analizidir. "Dokümanlar, yazılı halde bulunan metinlerden oluşan her tür doküman, görüntü ve ses kayıtları ile diğerleri kapsamında yer alan objeler, kalıntılar makro ve mikro düzeydeki veriler olarak gruplandırılır" (Y1ldırım ve Şimşek, 2013, s. 223).

Araştırmacılar Öğretim Programı'nda (MEB, 2018) tüm sınıflar düzeyinde yer alan her bir kazanımı 21. yüzyıl becerilerinin yaşam ve kariyer becerileri; öğrenme ve yenilikçilik becerileri; bilgi, medya ve teknoloji becerilerine göre içerik analizine tabi tutmuşlardır. "İçerik analizi, belirli kurallara dayalı kodlamalarla bir metnin bazı sözcüklerinin daha küçük içerik kategorileriyle özetlendiği, sistematik yinelenebilir bir teknik olarak tanımlanır” (Büyüköztürk, Kılıç Çakmak, Akgün, Karadeniz ve Demirel, 2014, s. 240). Koçak ve Arun'a göre (2006) içerik analizi farklı disiplinlerde birçok araştırma sorusuna yanıt aramak üzere kullanılan temel bir araştırma aracıdır, ayrıca içerik analizinin farklı tanımları olmasına rağmen bu tanımların tamamında vurgulanan iki önemli konu yöntemin "sistematik" ve "tarafsız" olması gerektiğidir. Kazanımlar, çalışmada adı yer alan her iki araştırmacı tarafından ayrı ayrı incelenmiş, yapılan incelemede kod güvenirliğinin sağlanması için Miles ve Huberman'ın (1994) aşağıda verilen formülünden yararlanılmıştır: 


$$
\text { Güvenirlik }=\frac{\text { görüș birliğ } i}{\text { görüş birliği }+ \text { görüş ayrıllğ } 1} \times 100
$$

Yapılan hesaplamada araştırmacılar arasındaki görüş birliği \%91,6 olarak bulunmuştur. İncelemede araştırmacıların farklı şekilde kodladıkları bölümler tekrar gözden geçirilmiş ve gerekli uzlaşma sağlanarak görüş birliğine varılmış, böylece incelemeye nihai hâli verilmiştir.

\section{Bulgular}

Çalışmada içerik analizine tabi tutulan 21. yüzyıl becerilerinin (Yaşam ve Kariyer Becerileri; Öğrenme ve Yenilikçilik Becerileri; Bilgi, Medya ve Teknoloji Becerileri) 2018 Türkçe Dersi Öğretim Programı 1, 2, 3, 4, 5, 6, 7 ve 8. sınıf dinleme/izleme, konuşma, okuma (akıcı okuma, söz varlığ ve anlama), yazma kazanımlarında hangi oranlarda yer aldığıyla ilgili bilgiler aşağıda her bir ana başlığa bağlı tablolaştırılarak aktarılmıştır.

\section{Tablo 1}

\begin{tabular}{|c|c|c|c|c|c|c|c|}
\hline 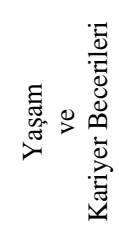 & 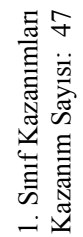 & 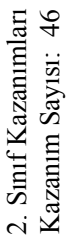 & 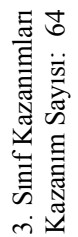 & 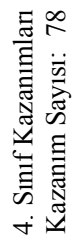 & 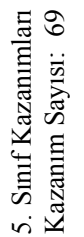 & 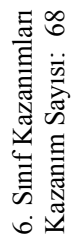 & 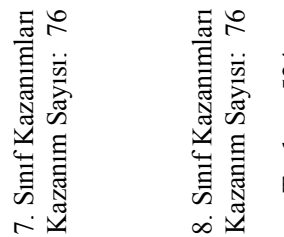 \\
\hline
\end{tabular}

Öğretim Programında Yer Verilen 21. Yüzyıl Yaşam ve Kariyer Becerileri
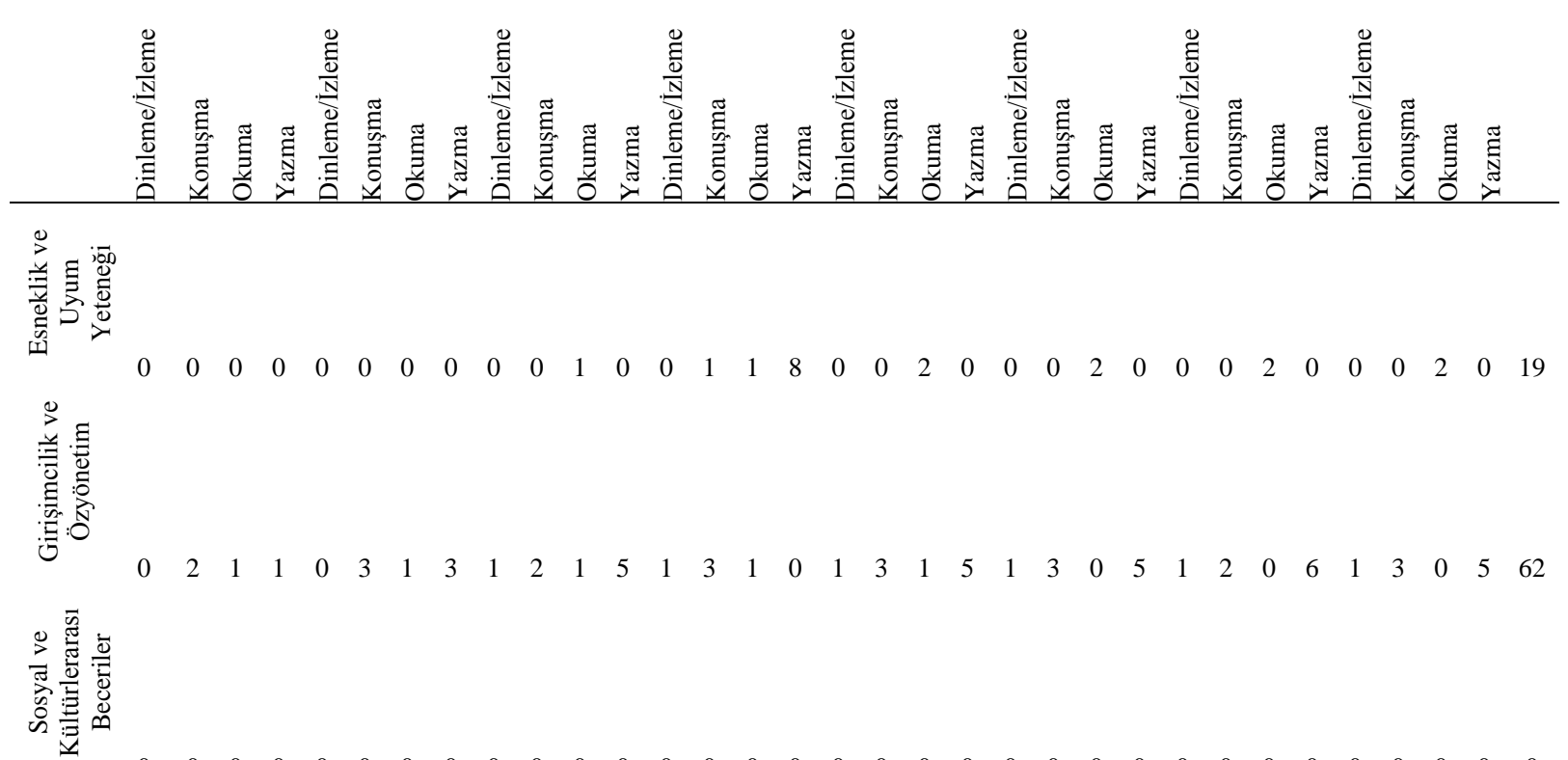

$\begin{array}{llllllllllllllllllllllllllllllllll}0 & 0 & 0 & 0 & 0 & 0 & 0 & 0 & 0 & 0 & 0 & 0 & 0 & 0 & 0 & 0 & 0 & 0 & 0 & 0 & 0 & 0 & 0 & 0 & 0 & 0 & 0 & 0 & 0 & 0 & 0 & 0 & 0\end{array}$

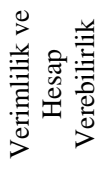

$\begin{array}{llllllllllllllllllllllllllllllllllllll}0 & 0 & 0 & 1 & 0 & 0 & 0 & 1 & 0 & 0 & 0 & 1 & 0 & 0 & 0 & 1 & 0 & 0 & 0 & 1 & 0 & 0 & 0 & 1 & 0 & 0 & 0 & 3 & 0 & 0 & 0 & 3 & 12\end{array}$

\begin{tabular}{|c|c|c|c|c|c|c|c|c|c|c|c|c|c|c|c|c|c|c|c|c|c|c|c|c|c|c|c|c|c|c|c|c|c|}
\hline . & 0 & 0 & 0 & 1 & 0 & 0 & 0 & 1 & 0 & 0 & 0 & 1 & 0 & 1 & 0 & 1 & 0 & 0 & 0 & 1 & 0 & 0 & 0 & 1 & 0 & 0 & 0 & 2 & 0 & 0 & 0 & 2 & 11 \\
\hline 丞 & & & & & & & & & & & & & & & & 1 & & & & & & & & & & & & 1 & & & & 1 & 10 \\
\hline$\stackrel{0}{\ominus}$ & 0 & 2 & 1 & 3 & 0 & 3 & 1 & 5 & 1 & 2 & 2 & 7 & 1 & 5 & 2 & 0 & 1 & 3 & 3 & 7 & 1 & 3 & 2 & 7 & 1 & 2 & 2 & 1 & 1 & 3 & 2 & 0 & 4 \\
\hline
\end{tabular}

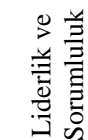


Tablo 1'e göre 524 toplam kazanım arasında "Yaşam ve Kariyer Becerileri”ne 104 kez temas edildiği tespit edilmiştir. 21. yüzyıl yaşam ve kariyer becerilerinin alt boyutlarına yönelik yapılan incelemede "esneklik ve uyum yeteneği" alt boyutuna 524 kazanım arasında toplamda 19 kez temas edildiği, 1 ve 2 . sınıflarda bu becerilere kazanımlarda hiç yer verilmediği, 3. sınıflarda 1, 4. sınıflarda $10 \mathrm{kez}$ yer verilirken 5, 6, 7 ve 8. sınıflarda yalnızca ikişer kez okuma kazanımlarında yer verildiği görülmüştür.

Programda bu beceri, "T.5.3.15. Metinde ele alınan sorunlara farklı çözümler üretir." ve “T.5.3.17. Metni yorumlar (MEB, 2018, s. 36)." kazanım ifadeleri olarak karşımıza çıkmaktadır.

Yapılan incelemede esneklik ve uyum yeteneğinin kazanımlara olan dağılımında herhangi bir denge gözetilmediği tespit edilmiştir.

"Girişimcilik ve özyönetim” alt boyutuna 524 kazanım arasında toplamda 62 kez yer verildiği, en çok temas edilen alt boyutun bu olduğu ayrıca bu beceriye tüm sınıflarda yer verildiği görülmektedir. Becerilerin sınıflar bazındaki dağılımına bakıldığında sınıflar arasında sabit bir denge olmasa da 1 ve 4 . sınıflar dışında kazanım sayılarının birbirine yakın olduğu dikkati çekmektedir.

“T.7.4.17. Yazdıklarını paylaşı (MEB, 2018, s. 46)." kazanımı ve açıklamasında yer alan "Öğrenciler yazdıklarını sınıf ve okul panosu ile sosyal medya ortamlarında paylaşmaya, şiir ve kompozisyon yarışmalarına katılmaya teşvik edilir." açıklamasında öğrencilerin girişimci davranışlar sergileyecekleri fikri üzerinden hareket edilmiştir.

Bir diğer alt başlık olan "sosyal ve kültürlerarası beceriler"e bakıldığında 524 kazanım arasında hiçbir sınıf düzeyinde bu becerilere yer verilmediği görülmüştür. "Verimlilik ve hesap verebilirlik" alt boyutuna bakıldığında ise 524 kazanım arasında bu beceriye toplamda $12 \mathrm{kez}$ temas edildiği; 1, 2, 3, 4, 5 ve 6 . sinıflarda yalnızca yazma kazanımlarında birer kez bu beceriye yer verilirken 7 ve 8 . sinıflarda üçer kez temas edildiği tespit edilmiştir.

“T.8.4.16. Yazdıklarını düzenler (MEB, 2018, s. 50)." kazanımı ve bu kazanımın açıklaması olan "Dil bilgisine dayalı anlatım bozuklukları bakımından yazdıklarını gözden geçirmesi ve düzeltmesi sağlanır." İfadesinde yazılı anlatım ürünü ortaya koyma yoluyla verimli olma ve yazdıklarının sorumluluğunu üzerine alarak gerekli gördüğü yerde düzeltmeler yapma yoluyla hesap verebilir olma durumu göz önünde bulundurulmuştur.

Yaşam ve kariyer becerilerine ait son alt başlık olan "liderlik ve sorumluluk" alt becerisine bakıldığında bu beceriye 524 kazanım arasında toplamda $11 \mathrm{kez}$ yer verildiği, 4. sınıflarda bir kez konuşma kazanımında yer verilmesinin haricinde tüm sınıflarda sadece yazma kazanımlarında bu beceriye temas edildiği görülmektedir.

"T.4.2.3. Hazırlıklı konuşmalar yapar (MEB, 2018, s. 30)." kazanımı ve bu kazanımın "Öğrencilerin verilen bir konuyu görsellerle destekleyerek kısa sunum hazırlamaları ve prova yapmaları sağlanır.” şeklindeki açıklamasında yapılacak olan sunum hazırlama yoluyla sorumluluk alma durumu üzerinden hareket edilmiştir. 


\section{Tablo 2}

Öğretim Programında Yer Verilen Ö̆grenme ve Yenilikçilik Becerileri

\begin{tabular}{|c|c|c|c|c|c|c|c|c|c|}
\hline 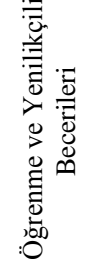 & 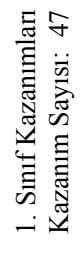 & 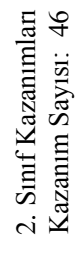 & 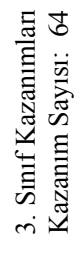 & 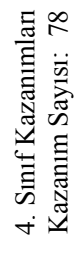 & 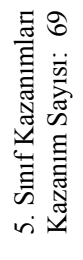 & 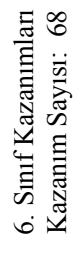 & 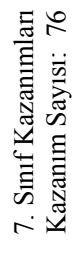 & 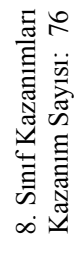 & 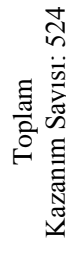 \\
\hline
\end{tabular}

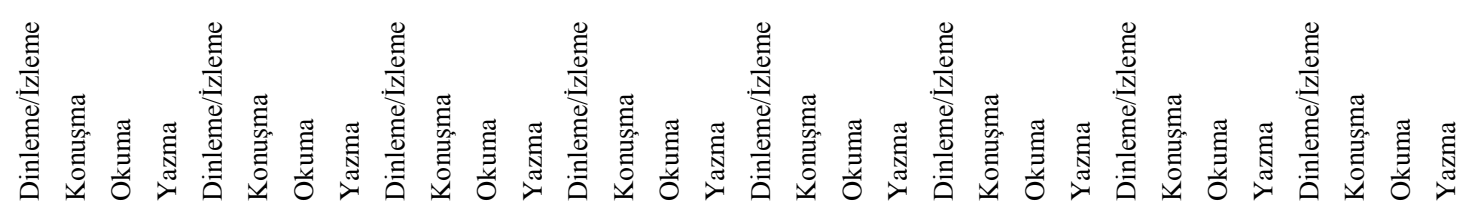

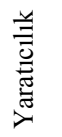

$\begin{array}{llllllllllllllllllllllllllllllllll}0 & 2 & 1 & 1 & 3 & 2 & 1 & 6 & 1 & 2 & 1 & 7 & 1 & 0 & 1 & 7 & 1 & 3 & 1 & 5 & 1 & 3 & 1 & 6 & 1 & 3 & 1 & 4 & 1 & 3 & 1 & 7 & 78\end{array}$

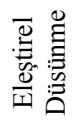

$\begin{array}{llllllllllllllllllllllllllllllllllll}1 & 0 & 2 & 1 & 2 & 0 & 2 & 1 & 4 & 0 & 7 & 0 & 2 & 1 & 0 & 0 & 3 & 3 & 1 & 3 & 5 & 1 & 0 & 2 & 6 & 1 & 3 & 2 & 7 & 1 & 2 & 2 & 116\end{array}$

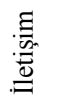

$\begin{array}{llllllllllllllllllllllllllllllllll}1 & 3 & 0 & 1 & 4 & 3 & 1 & 4 & 1 & 4 & 0 & 5 & 1 & 2 & 0 & 8 & 3 & 4 & 1 & 5 & 4 & 4 & 1 & 9 & 4 & 4 & 1 & 8 & 4 & 4 & 1 & 9 & 104\end{array}$

赵

$\begin{array}{lllllllllllllllllllllllllllllllllll}0 & 0 & 0 & 0 & 0 & 0 & 0 & 0 & 0 & 0 & 0 & 0 & 0 & 0 & 0 & 0 & 1 & 1 & 0 & 1 & 1 & 1 & 0 & 0 & 1 & 1 & 1 & 0 & 0 & 1 & 0 & 0 & 9\end{array}$

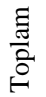

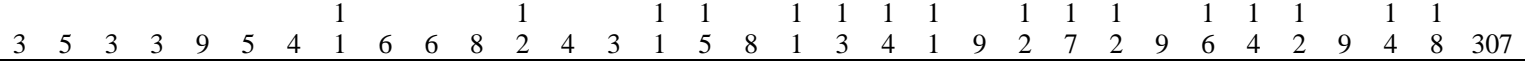

Tablo 2'ye göre öğrenme ve yenilikçilik becerilerinin alt boyutlarından birincisi olan "yaratıcılık" becerisine bakıldığında 524 toplam beceri arasında bu beceriye 78 kez yer verildiği, 1 . sınıf dinleme/izleme ve 4. sınıf konuşma kazanımları dışında tüm alanlarda bu becerilere yer verildiği görülmüştür. 1. sınıflardaki bu beceriye 4 kez yer verilirken diğer sınıflarda yaratıcılık kazanımına temas edilme sayısının 9 ve 12 sayıları arasında değiştiği tespit edilmiştir.

Bu bölümde, “T.6.1.8. Dinlediği/izlediği hikâye edici metinleri canlandırır (MEB, 2018, s. 39).” kazanımında olduğu gibi ortaya konulacak faaliyet, eser ve fikirlerde yaratıc1lık becerisinin sergilenmesi gerektiği fikri üzerinden hareket edilmiştir.

Tabloya ait bir diğer alt başlık olan "eleştirel düşünme" becerisine bakıldığında 524 kazanım arasında bu beceriye toplamda $116 \mathrm{kez}$ temas edildiği; 1,2 ve 4 . sınıf konuşma becerileri ile 3 . sınıf konuşma ve yazma becerileri dışında tüm alanlarda bu becerilere yer verildiği görülmüştür. 
Bu bölümde, "T.5.3.17. Metni yorumlar (MEB, 2018, s. 30)." kazanımı yenilik becerileri ile ilgilidir. Ayrıca bu kazanımın açıklaması olarak da ilgili programda şu ifade yer almaktadır: "Yazarın bakış açısını fark etmeleri, olayları ele alışs şeklini yorumlamaları ve ögrencilerin metinle ilgili kendi bakış açılarını ifade etmeleri sağlanır (MEB, 2018, s. 36).” Bu kapsamda öğrencilerin kendi bakış açılarını ortaya koymak için eleştirel düşünme becerisinden yararlanmaları gerektiği vurgulanmıştır.

Öğrenme ve yenilikçilik becerilerinin üçüncü boyutu olan iletişim becerisi açısından kazanımlara bakıldığında ise 524 kazanım arasında bu beceriye toplamda 104 kez temas edildiği; 1, 3 ve 4. sınıf okuma kazanımları dışında tüm alanlarda bu beceriye yer verildiği görülmektedir. Burada, "T.4.4.12. Yazdıklarını paylaşır (MEB, 2018, s. 33)." kazanımı ve açıklamasında (Öğrenciler yazdıklarını sını içinde okumaları, okul veya sınıf panosunda sergilemeleri için teşvik edilir. Öğrencilere yazdıklarını sınıf içinde okumaları konusunda ısrar edilmemelidir.) olduğu gibi yazmanın iletişim kurmanın önemli bir boyutu olduğu yönüyle hareket edilmiştir.

Bu bölüme ait son alt başlık olan "iş birliği”" becerisi açısından kazanımlara bakıldığında 524 kazanım arasında iş birliğine sadece 9 kez yer verildiği, bu bölümün diğer üç alt başlığına ve toplam kazanım sayısına kıyasla gerek toplamda gerekse diğer alt becerilere temas edilme sayısında iş birliği becerisinin oldukça az ( $\mathrm{f}=9$ ) olduğu görülmektedir. Bunun yanında 1, 2, 3 ve 4 . sinıflarda bu beceriye hiç değinilmemiş olması da dikkat çekicidir. İş birliği becerisinin tespitinde,

"T.5.1.12. Dinleme stratejilerini uygular." Kazanımı ve bu kazanımın açıklasında yer alan "Not alarak, katılıml, grup hâlinde dinleme gibi yöntem ve teknikleri uygulamaları sağlanır (MEB, 2018, s. 35)." ifadelerinde olduğu gibi yapılacak faaliyette iş birliği içerisinde hareket etmek gerektiği görüşü temel alınmıştır.

Tablo 3. Öğretim Programında Yer Verilen Bilgi, Medya ve Teknoloji Becerileri

\begin{tabular}{|c|c|c|c|c|c|c|c|c|c|}
\hline 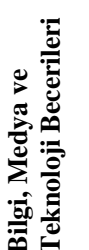 & 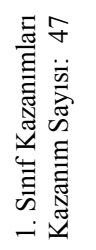 & 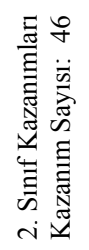 & 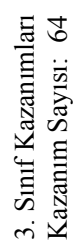 & 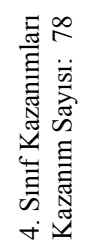 & 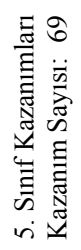 & 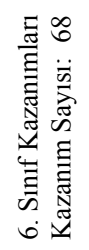 & 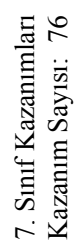 & 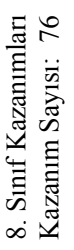 & 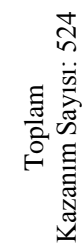 \\
\hline
\end{tabular}

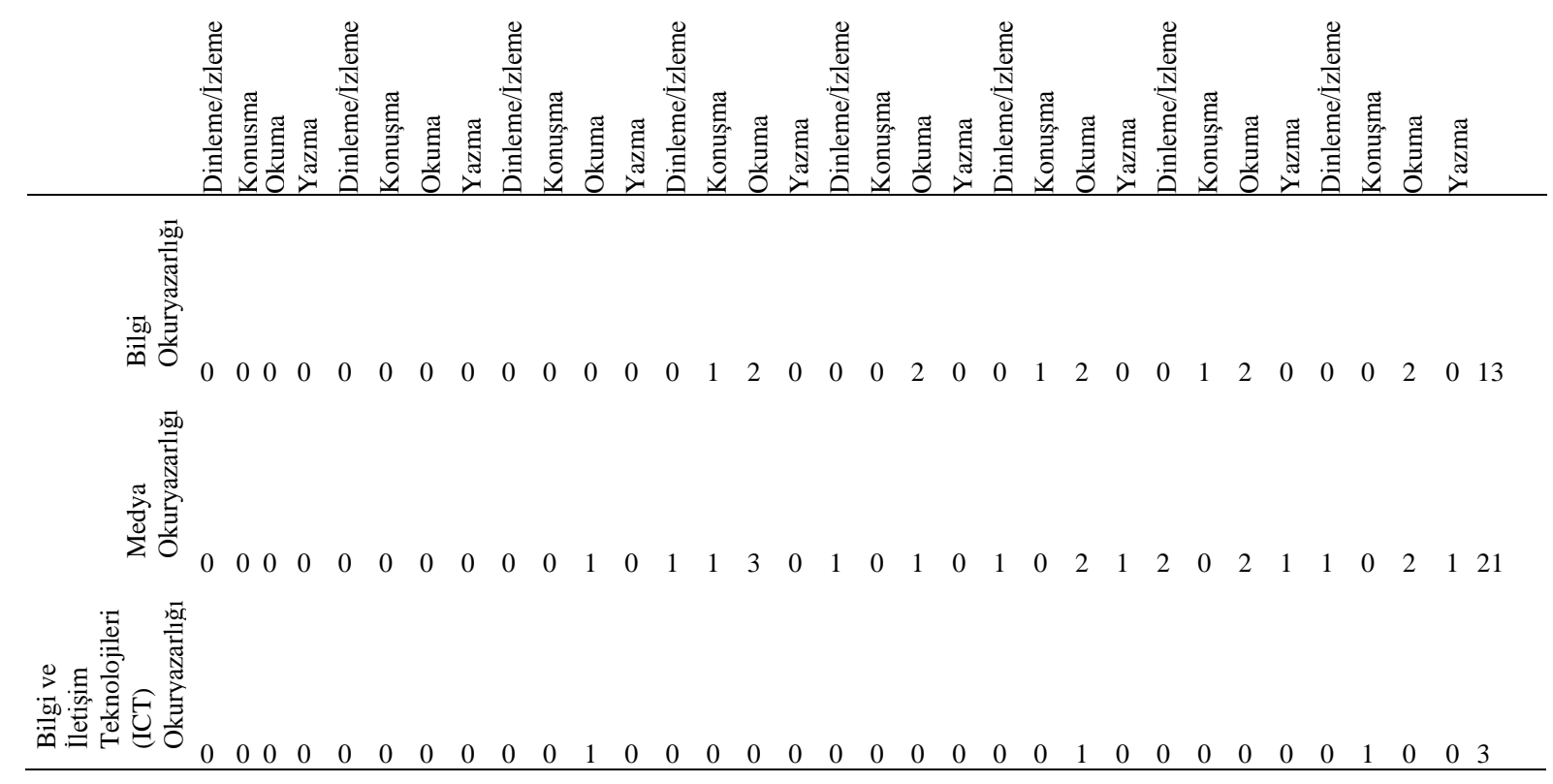


ह $\begin{array}{lllllllllllllllllllllllllllllllll}0 & 0 & 0 & 0 & 0 & 0 & 0 & 0 & 0 & 0 & 2 & 0 & 1 & 2 & 5 & 0 & 1 & 0 & 3 & 0 & 1 & 1 & 5 & 1 & 2 & 1 & 4 & 1 & 1 & 1 & 4 & 1 & 37\end{array}$

Tablo 3'e göre bilgi, medya ve teknoloji becerileri ana başlığına 524 kazanım arasında yalnızca $37 \mathrm{kez}$ yer verilmiş olduğu tespit edilmiştir. Buna göre üç ana başlık arasında en az yer verilen becerilerin bilgi, medya ve teknoloji becerileri olduğu görülmektedir. Bu bölüme bağli birinci alt başlık olan "bilgi okuryazarlı̆̆ı"na 1, 2 ve 3. sınıflarda hiç yer verilmediği, diğer sınıflarda ise iki ya da üçer kez yalnızca okuma ve konuşma becerilerindeki kazanımlarda bu beceriye temas edildiği görülmektedir.

Burada, “T.4.3.35. Bilgi kaynaklarını etkili bir şekilde kullanır.” kazanımı ve bu kazanımın açıklaması (Bilgiye erişmek için basılı ve dijital içeriklerdeki içindekiler ve sözlük bölümünden nasıl yararlanılacağına ilişkin bilgi verilir.)" ile "T.4.3.36. Bilgi kaynaklarının güvenilirliğini sorgular." kazanımı ve bu kazanımın açıklamasında yer alan "Yazılı kaynakların (dergi, kitap, broşür, gazete vb.) incelenmesi ve değerlendirilmesi sağlanır (MEB, 2018, s. 32).” olduğu gibi doğrudan bilgi okuryazarlığına temas eden kazanımların tespiti üzerinden tablolaştırma yapılmıştır.

Bir diğer alt başlık olan "medya okuryazarlığı"na bakıldığında ise 1 ve 2 . sınıflarda bu beceriye hiç yer verilmezken kalan sınıflarda $21 \mathrm{kez}$ bu beceriye temas edildiği ancak dinleme/izleme, konuşma, okuma ve yazma kazanımlara dağılımında bir denklik gözetilmediği tespit edilmiştir.

Bu bölümde, "T.8.3.29. Medya metinlerini analiz eder (MEB, 2018, s. 49." kazanımı ve açıklaması (Medya metinlerinin amaçlarının (kültür aktarma, olay yorumlama, bilgilendirme, eğlendirme, ikna etme) belirlenmesi sağlanır.) medya okuryazarlığı açısından değerlidir.

Bilgi, medya ve teknoloji becerilerine bağlı son alt başlık olan bilgi ve iletişim teknolojileri (ICT) okuryazarlığı açısından yapılan incelemede ise 1, 2, 4, 5 ve 7. sınıf kazanımlarında bu beceriye hiç temas edilmezken 3 ve 6 . sınıf okuma, 8. sınıf konuşma kazanımlarında yalnızca birer kez olmak üzere toplamda $3 \mathrm{kez}$ bu becerilere yer verildiği görülmüştür.

\section{Sonuç}

2018 yılında güncellenen Türkçe Dersi Öğretim Programı'na (İlkokul ve Ortaokul 1, 2, 3, 4, 5, 6, 7 ve 8. Sinıflar) ait her bir kazanımın P21'in çerçevesindeki becerilere uygunluğu bakımından incelendiği bu çalışmada, öğretim programında yer alan 524 ayrı kazanım çerçevede yer alan üç ayrı ana başlığa (Yaşam ve Kariyer Becerileri; Öğrenme ve Yenilikçilik Becerileri; Bilgi, Medya ve Teknoloji Becerileri) bağlı her bir alt başlık (Esneklik ve uyum yeteneği, girişimcilik ve özyönetim, sosyal ve kültürlerarası beceriler, verimlilik ve hesap verebilirlik, liderlik ve sorumluluk; yaratıcılık, eleştirel düşünme, iletişim, iş birliğii; bilgi okuryazarlı̆̆ 1 , medya okuryazarlığ teknolojileri okuryazarlığı) için ayrı ayrı incelenmiştir. Yapılan incelemede 524 toplam kazanım arasında "Yaşam ve Kariyer Becerileri"ne 104; öğrenme ve yenilikçilik becerilerine 307; bilgi, medya ve teknoloji becerilerine yalnızca $37 \mathrm{kez}$ yer verilmiş olduğu tespit edilmiştir. Dolayısıyla programın (MEB, 2018) kazanımlarının dağılımında 21. yüzyıl becerilerinin göz önünde bulundurulmadığı, becerilerin kazanımlara dağılımında herhangi bir dengenin gözetilmediği sonucuna ulaşılmıştır. İçinde bulunduğumuz çağda teknoloji kullanımındaki yoğunluğa bakılarak öğretim programlarında diğer becerilerle birlikte özellikle bilgi, medya ve teknoloji becerilerine verilmesi gereken önem ortadayken mevcut programda (MEB, 2018) en az yer verilen beceri grubunun bilgi, medya ve teknoloji becerileri olması dikkat çekicidir. Yapılan inceleme Bal'ın (2018) "21. yüzyıl becerilerinin dağılımına bakıldığında da belli bir oranın olmadığı" ayrıca "programın temel becerileri alanında her ne kadar 21. 
yüzyıl becerileri öne çıkarılsa da kazanım boyutunda eksiklikler olduğu" görüşleriyle örtüşmektedir. Bunun yanında bu araştırmada en çok temas edilen beceri grubunun öğrenme ve yenilikçilik becerileri olması Bektaş, Sellum ve Polat'ın (2019) 2018 Hayat Bilgisi Dersi Öğretim Programı'nda iletişim ve iş birliği becerilerine yer verilmeye özen gösterildiği sonucuyla benzerlik gösterirken eleştirel düşünme ve yaratıcı düşünme becerilerine ise sınırlı olarak yer verildiği sonucu da bu araştırmada üzerinde durulan, becerilerin dağılımında belirli bir planlama üzerinden hareket edilmediği sonucuyla uyum göstermektedir.

Voogt ve Roblin (2010) yeni ve eski beceriler arasındaki bağlantıların henüz netleşmemiş olmas1 sebebiyle 21. yüzyıl becerilerinin geleneksel müfredattaki yerinin belirsiz olduğunu savunmuşlardır. Ayrıca 21. yüzyıl becerilerinin mevcut müfredatla bağlantısının ne olduğunu, bütün bu becerilerin zorunlu eğitim müfredatının bir parçası olup olmadığının da aynı şekilde belirsiz olduğunu, şayet gerekiyorsa programlarda becerilere ne kadar yer açılması gerektiğini tartışmaya açmışlardır. Ancak öğretim programları, hem çağın ihtiyaçlarına cevap verecek hem de öğretim ortamlarında yer alan bireyleri geleceğe hazırlayacak şekilde gerektiği dönemlerde güncellenmelidir. Ülkemiz programları da bu ihtiyaçlar doğrultusunda 2005, 2015, 2017 ve 2018 yılında güncellenmiştir. Yapılan güncellemelerde programlarda anahtar yetkinliklerin ön plana çıktığı görülmektedir. Buna karşın Milli Eğitim Bakanlığının 2023 Vizyonu'nda yer alan “21. Yüzyıl Becerileri”nin programımızda (MEB, 2018) yeterli ve dengeli bir şekilde yer almadığı görülmektedir. Özetle öğrencilerimizi modern dünyayla yarışacak nitelikli bireyler hâline getirmesi bakımından önem arz eden 21. yüzyıl becerilerine programlarımızda sistemli bir şekilde yer verilmesi gerekmektedir.

Açıklama: Bu makale XI. Uluslararası Türkçenin Eğitimi Öğretimi Kurultayı'nda sunulan bildirinin genişletilmiş hâlidir. 


\section{Kaynaklar}

Abao, E., Dayagbil, F. and Boholano, H. (2015). Engagement to social networking: challenges and op portunities to educators. European Scientific Journal, 11(16), 173-191.

Bal, M. (2018). Türkçe dersinin 21. yüzy1l becerileri açısından incelenmesi. Turkish Studies,13(4), 4964.

Bektaş, M., Sellüm, F. ve Polat, D. (2019). 2018 hayat bilgisi dersi öğretim programının 21. yüzyıl öğrenme ve yenilikçilik becerileri açısından incelenmesi. Sakarya University Journal of Education, 9(1), 129-147.

Bialik, M. and Fadel, C. (2015). Skills for the 21st century: what should students learn. Boston: Center for Curriculum Redesign.

Büyüköztürk, Ş., Kılıç Çakmak, Akgün, Ö. E., Karadeniz, Ş. ve Demirel, F. (2014). Bilimsel araştırma yöntemleri. Ankara: PegemA Yayınc1lık.

Ercikan, K. and Oliveri, M. E. (2016). In search of validity evidence in support of the interpretation and use of assessments of complex constructs: Discussion of research on assessing 21st century skills. Applied Measurement in Education, 29(4), 310-318.

Koçak, A. ve Arun, Ö. (2006). İçerik analizi çalışmalarında örneklem sorunu. Selçuk Iletetişim, 4(3), 2128.

Kurudayığlu, M. ve Soysal, T. (2018). Beşinci sınıf Türkçe ders kitabının Türkçe dersi öğretim programındaki temel becerilere uygunluğu açısından incelenmesi. Yeni Türkiye Türk Dili Özel Sayısı II, 24(100), 458-469.

Lamb, S., Maire, Q. and Doecke, E. (2017). Key skills for the 21st century: an evidence-based review. New South Wales: Education Future Frontiers.

McCoog, I.J. (2008). 21st century teaching and learning. Education Resource Center. tarihinde eric.ed.gov/PDFS/ED502607.pdf adresinden alınmıştır.

MEB. (2018). Türkçe dersi öğretim programı (ilkokul ve ortaokul 1, 2, 3, 4, 5, 6, 7 ve 8. sınıflar). Ankara.

MEB. (2018). Mutlu çocuklar güçlü Türkiye, MEB 2023 eğitim vizyonu. Ankara.

Miles, M. B. and Huberman, A. M. (1994). Qualitative data analysis: an expanded sourcebook. California: Sage Publications.

Saavedra, A. R. and Opfer, V. D. (2012). Teaching and learning 21st century skills. USA: Asia Society.

Temizkan, M. (2014). Ortaokul Türkçe ders kitaplarının Türkçe dersi öğretim programındaki temel beceriler açısından incelenmesi. Ana Dili Eğitimi Dergisi, 2(1), 49-72.

Voogt, J. and Roblin, N. P. (2010). 21 st century skills discussion paper. Netherlands: Enschede.

Yıldırım, A. ve Şimşek, H. (2013). Sosyal bilimlerde nitel araştırma yöntemleri. Ankara: Seçkin Yayınları.

Yıldırım, A. ve Şimşek, H. (2016). Sosyal bilimlerde nitel araştırma yöntemleri. Ankara: Seçkin Yayınları. 


\section{Extended Abstract}

\section{Introduction}

The rapid change that took place in the age we live in has made certain changes in the society obligatory and new needs emerged from education to social life. At this point, 21 st century skills appear.

According to the framework prepared by $\mathrm{P} 21$, we see that the skills are grouped under three main headings. These are;

\section{Life and Career Skills}

- $\quad$ Flexibility and Adaptability

- $\quad$ Initiative and Self-Direction

- $\quad$ Social and Cross-Cultural Skills

- $\quad$ Productivity and Accountability

- $\quad$ Leadership and Responsibility

Learning and Innovation Skills

- $\quad$ Creativity

- $\quad$ Critical Thinking

- Communication

- Collaboration

Information, Media and Technology Skills

- Information Literacy

- $\quad$ Media Literacy

- Information, Communication and Technology Literacy

Given the importance of 21st century skills in teaching environments, the aim of this study is to examine each gain of the Turkish Language Teaching Program updated in 2018 in terms of its suitability to the skills within the framework of P21.

\section{Method}

The study was designed qualitatively. Accordingly, the gains of 2018 Turkish Lesson Teaching Curriculum (Grade 1, 2, 3, 4, 5, 6, 7 and 8) at all grades were subjected to "document analysis", one of the methods of qualitative research methods, in accordance with life and career skills, learning and innovation skills, information, media and technology skills of the 21 st century skills.

The researchers have subjected each gain at all grade levels in the Teaching Curriculum (MEB, 2018) to content analysis according to life and career skills, learning and innovation skills, information, media and technology skills of the 21 st century skills. The gains were analyzed separately by both researchers named in the study and Miles and Huberman's (1994) formula was used in order to ensure code reliability.

$$
\begin{aligned}
& \text { Reliability }=\underline{\text { number of agreement }} \times 100 \\
& \text { number of agreement }+ \text { number of disagreement }
\end{aligned}
$$

In the calculation, the agreement among the researchers was found to be $91.6 \%$. In the review, the sections coded differently by the researchers were reviewed and consensus was reached by reaching the necessary agreement, thus finalizing the review. 


\section{Findings}

Among 524 gains, it was observed that 104 of them pointed out the "Life and Career Skills". In the study conducted on the 21st century life and career skills sub-dimensions, it was seen that among 524 gains Flexibility and Adaptability sub-dimension was touched on 19 times, that these skills were not included in the gains of the grade 1 and 2 curriculum, that they were included once in the curriculum of grade 3, ten times in grade 4 and only twice in those of grades 5, 6, 7 and 8. In the study, it was found that no balance was observed in the distribution of flexibility and adaptability skill to gains.

It is seen that "Initiative and Self-Direction" sub-dimension is given 62 times in total out of 524 gains, this is the most contacted sub-dimension and this skill is included in all classes. Considering the distribution of skills on the basis of classes, it is noteworthy that although there is no fixed balance between classes, the numbers of gains are close to each other except grades 1 and 4 .

When we look at another subheading, "Social and Cross-Cultural skills, it was observed that these skills were not included at any grade level among 524 gains. Looking at the "Productivity and Accountability" sub-dimension, it was found that this skill was contacted 12 times in total between 524 gains; In the 1, 2, 3, 4, 5 and 6, this skill was used only once for writing gain, and three times in the grades 7 and 8 .

When the "Leadership and Responsibility" sub-skill, which is the last sub-title of life and career skills, is examined, it is seen that this skill is given 11 times in total among 524 gain and that this skill is touched only in writing gain in all grades except once in speaking gainin grade 4.

When the "Creativity" skill which is the first of the sub-dimensions of learning and innovation skills is examined, it is seen that this skill is given 78 times among 524 total skills, and these skills are included in all fields except grade 1 listening / monitoring and 4th grade speaking gain. While this skill was given 4 times in grade 1, it was found that the number of contacting creativity gain in the other grades ranged between 9 and 12 .

When looked at the "Critical Thinking" which is another sub-heading, it was revealed that this skill is touched on 116 times among 524 skills and that this skill has been taken place in all areas except grade 1, 2 and 4 speaking skills and grade 3 writing skills. When the gains are examined in terms of communication skill which is the third dimension of learning and innovation skills, it is seen that this skill is referred 104 times among 524 skills and that it was included in all areas except grade 1, 3 and 4 reading gains.

When looked at the gains "Collaboration" which is the final sub-heading of this area, it is seen that this skill is mentioned only 9 times and the number of reference to both sub-dimensions and in total is relatively low $(\mathrm{f}=9)$ compared to other three sub-heading of this area and to the total number of gains. In addition, it is noteworthy that this skill is not mentioned at all in grade 1, 2, 3 and 4.

It was observed that the main heading of Information, Media and Technology Skills are touched on only 37 times out of 524 gains. Accordingly, it is seen that information, media and technology skills are the least mentioned group among three main areas. It is seen that information literacy, which is the first sub-title of this section, is not included in the grade 1,2 and 3, and in other grades it is touched twice or three times only in the gains of reading and speaking skills.

In terms of media literacy, which is another subheading, it was found that this skill was not included in grade 1 and 2, but that skill was contacted 21 times in the remaining classes, but no equivalence was observed in the distribution of listening / monitoring, speaking, reading and writing gains. 
In terms of Information and Communication Technologies (ICT) literacy, which is the last subtitle of this section, this skill was not touched in the grade 1,2, 4, 5 and 7 gains, while the grade 3 and 6 readings and 8 speech gains were touched only once. These skills were mentioned 3 times in total.

\section{Results}

In this study, where each acquisition of Turkish Language Teaching Program (Primary and Secondary Schools Grade 1, 2, 3, 4, 5, 6, 7 and 8) updated in 2018 was examined in terms of the suitability of the skills within the framework of P21, it was observed that among 524 total gains, "Life and Career Skills" are included 104 times, that "Learning and Innovation Skills" are included 307 times and that "Information, Media and Technology Skills" are mentioned only 37 times.

Therefore, it was concluded that the 21st century skills were not taken into consideration in the distribution of the program's gains (MEB, 2018) and that no balance was taken into consideration in the distribution of the skills. 